\title{
A Pandemia E A Adaptação Do Ensino Remoto Em Uma Escola Do/No Campo De Nova Santa Rita/Rs
}

\section{Pandemic and the Adaptation of Remote Learning in a Rural School in Nova Santa Rita/Rs}

\section{Sabrina Silveira da Rosa \\ Mestra em Educação em Ciências \\ Instituição atual: Emef Rui Barbosa \\ Professora de Séries Iniciais e Educação Física \\ E-mail: ssrosa2001@yahoo.com.br}

\section{Andressa Luana Moreira Rodrigues}

Mestra em Educação em Ciências

Instituição atual: Emef Rui Barbosa

Endereço: Estrada Fazenda Capela s/n, Sanga Funda, Nova Santa Rita/RS

E-mail: andressaluana.mr@hotmail.com

\section{Mariana Paranhos de Oliveira}

Mestra em Educação em Ciências

Instituição atual: Universidade Federal do Rio Grande do Sul

Gama, 110, Anexo I da Reitoria, Térreo, Porto Alegre-RS

E-mail: marianaparanhosdeoliveira@hotmail.com

\section{Maria do Rocio Fontoura Teixeira}

Doutora em Educação em Ciências

Instituição atual: Universidade Federal do Rio Grande do Sul e Universidade 90035-007 - Porto Alegre, RS - Brasil

E-mail: maria.teixeira@ufrgs.br

\section{José Vicente Lima Robaina}

Pós-Doutor em Educação e Educação do Campo

Instituição atual: Universidade Federal do Rio Grande do Sul e Universidade

Estadual do Rio Grande do Sul

Av. Paulo Gama, s/n prédio 12201 sala 825

Farroupilha

90046900 - Porto Alegre, RS - Brasil

E-mail: joserobaina1326@gmail.com

\section{RESUMO}

O presente trabalho relata a experiência de uma escola do/no Campo que se localiza dentro de um assentamento do MST (Movimento dos Trabalhadores Sem Terra) de uma cidade da região metropolitana de Porto Alegre, durante o período 
de pandemia da COVID-19. Após estudos de como elaborar as apostilas para entrega das atividades aos educandos da escola em análise, pode-se perceber que as atividades remotas durante a pandemia trouxeram muitas reflexões sobre o modelo de educação que temos, pois durante esse momento ficou evidente 0 quanto é necessário a parceria entre família e escola e o quanto a presença do professor é fundamental para a aprendizagem dos educandos. Percebeu-se que a implementação do ensino remoto tornou ainda mais evidente a precariedade da vida dos alunos e professores das escolas públicas brasileiras, e como as condições de desigualdade afetam o acesso à educação e seu desenvolvimento.

Palavras-chave: Ensino remoto, Educação do/no Campo, Pandemia.

\section{RESUMEN}

El presente trabajo relata la experiencia de una escuela en el campo que se encuentra dentro de un asentamiento del MST (Movimiento de los Trabajadores Rurales Sin Tierra) en una ciudad de la región metropolitana de Porto Alegre, durante el período de la pandemia. Luego de los estudios sobre cómo preparar los folletos para la entrega de actividades a los estudiantes de la escuela en análisis, se puede apreciar que las actividades a distancia durante la pandemia trajeron muchas reflexiones sobre el modelo educativo que tenemos, durante este momento se hizo evidente cuán necesario es el la colaboración entre la familia y la escuela y cómo la presencia del profesor es fundamental para el aprendizaje de los alumnos. Se percibió que la implementación de la enseñanza a distancia hizo aún más evidente la precariedad de la vida de los estudiantes y docentes en las escuelas públicas brasileñas, y cómo las condiciones de desigualdad afectan el acceso a la educación y su desarrollo.

Palabras clave: Enseñanza a distancia, Educación desde/en el campo, Pandemia.

\section{INTRODUÇÃO}

\subsection{EDUCAÇÃO DO/NO CAMPO}

A Educação do campo é a modalidade de ensino que deve ocorrer em espaços denominados rurais nos municípios. Diz respeito a todo espaço educativo que se dá em espaços fora da zona urbana como: florestas, regiões onde há o predomínio da agricultura e da agropecuária, populações ribeirinhas, caiçaras, extrativistas, assentamentos indígenas e comunidades quilombolas.

A educação do campo tem três grandes desafios: 1) assegurar o acesso dos camponeses ao conhecimento, 2) direito a diferença, 3) trabalhar um novo projeto no campo da elaboração e da disseminação do conhecimento que rompa a hegemonia do capital no campo. Segundo Arroyo (2005, p. 14) "todo o movimento social sabe que toca em consciência, valores, representações, 
preconceitos, culturas. Esta consciência do papel educativo e formador tem sido destacada nas experiências de formação de educadores".

O reconhecimento de que as pessoas que vivem no campo têm direito a uma educação diferente daquela oferecida para quem vive nas cidades é recente. Esse reconhecimento extrapola a noção de espaço geográfico e compreende as necessidades culturais, os direitos sociais e a formação integral desses indivíduos, tornando-se uma proposta inovadora no universo educacional. Para Caldart (2004, p.17) "o povo tem direito de ser educado no lugar onde vive; o povo tem direito a uma educação pensada desde o seu lugar e com participação, vinculada à sua cultura e às suas necessidades humanas e sociais".

Também sabemos que é inviável falar de educação do campo sem falar do MST, pois sabemos que aquela teve seu início a partir das lutas pela terra e depois passou a contemplar a luta pela educação e por uma transformação social por completo, de valorização do meio. Segundo Molina (2009, p.11), "A educação do campo originou-se no processo de luta dos movimentos sociais camponeses e, por isso, traz de forma clara sua intencionalidade: construção de uma sociedade sem desigualdades, com justiça social". A educação do campo fundamenta-se na preocupação da formação humana, com a emancipação e a consciência crítica, coletiva e atuante, objetivando a libertação de toda sociedade. Todas as discussões que permeiam a educação do campo, segundo (FREIRE, 2013), devem ser alicerçadas por pessoas do meio em que o campo está inserido, que represente o contexto, caso contrário será para o campo.

O município de Nova Santa Rita vem desenvolvendo estudos para a inserção de uma verdadeira escola do e no Campo, através de estudos e capacitações voltadas para as educadoras, gestoras e todo o coletivo educador. Após 7 anos de trabalhos de conhecimentos e apropriações sobre diferentes autores que são referências para um trabalho de qualidade nas escolas do/no Campo desta cidade, ficou inviável desenvolver qualquer material para as atividades remotas.

\subsection{EDUCAÇÃO DO/NO CAMPO E O ENSINO REMOTO}

Nos processos de ensino e aprendizagem, sabe-se que pouco ou quase nada pode ser considerado estático ou generalizado, porém nem todo esse 
desprendimento do inflexível preparou o mundo para a pandemia da Covid-19 que teve início em 2020. A pandemia provocou repercussões em vários aspectos da vida em escala global nos âmbitos sociais, econômicos, políticos, culturais, tecnológicos e saúde, fazendo com que os países adotassem medidas de isolamento social sem precedentes na história mundial. Todas essas mudanças afetaram diretamente o processo de escolarização de todas as crianças e adolescentes, em todas as etapas e níveis da educação formal, no Brasil e no mundo.

Com o avanço da pandemia, as aulas presenciais foram suspensas preventivamente, mas sem previsão de retorno. E agora? Neste contexto os organismos internacionais, como o Banco Mundial, instruíram a oferta de ensino remoto (COLETIVO, 2020). Não precisamos pesquisar muito a fundo para perceber que tais orientações desconsideram a realidade de um país que ocupa a $7^{\text {a }}$ colocação dos mais desiguais e que tem seu índice de desigualdade social em crescente desde o ano de 2014 (BERMÚDEZ; REZENDE; MADEIRO, 2020). Não subestimamos a contribuição das tecnologias atuais no campo educacional, mas como implementar o ensino remoto em um país que não garante direitos fundamentais como água potável, rede de esgoto, energia e transporte? Como implementar o ensino remoto se as crianças da escola do campo, muitas vezes, não possuem internet e hardwares para acompanhar a tecnologia atual?

Apesar de o isolamento social impactar diretamente todas as etapas da educação básica, definimos a educação infantil e os primeiros anos do ensino fundamental como campo de estudos, pois entendemos que os impactos causados para as crianças que estão nesta fase, são bastante pertinentes, tendo em vista que uma das competências e habilidades necessárias a ser adquirida para o bom desenvolvimento da criança é exatamente a interação social, e, também, por sermos educadoras dessa etapa escolar.

Diante dessas reflexões, este trabalho tem por objetivo traçar um panorama e investigar sobre o processo de ensino aprendizagem dos educandos das séries iniciais, na escola do Campo E.M.E.F Rui Barbosa, de Nova Santa Rita, durante o ano de 2020, marcado pela pandemia mundial da Covid-19. Trata-se de um estudo de cunho bibliográfico e descritivo, o qual se ateve para descrição dos dados, diários de escola das educadoras e as apostilas de atividades realizadas 
remotamente pelas crianças.

\section{CONTEXTO E DETALHAMENTO DO TRABALHO}

A escola de que falaremos nesse trabalho é uma escola do/no campo, de turno integral, que atende em torno de 80 crianças do ensino fundamental, do préescolar ao quinto ano, em turmas multisseriadas e está inserida nas dependências de um assentamento do Movimento dos Trabalhadores Rurais Sem Terra (MST). A mesma possui como eixo de interdisciplinaridade um Clube de Ciências - Clube de Ciências Saberes do Campo - o qual trabalha com diferentes temas sempre voltados a realidade dos educandos.

Com o retorno das férias de verão de 2020, a expectativa de um grande ano letivo se iniciava e foi em uma roda de conversa com os educandos sobre as férias e seus desejos para o ano de 2020 que surgiu na fala de uma das crianças: "profa! Tu viu o vírus que tem na China?", então, foi respondido muito simplesmente "Sim! Que horror né, pobre daquele país”. E assim, de forma muito rápida, seguimos com a aula normalmente, afinal o vírus não sairia de lá.

Na semana seguinte, começou-se a falar sobre o vírus e as preocupações da chegada dele em nosso país. A escola tem como hábito diário realizar uma acolhida para as crianças todos os dias, pela manhã, antes de entrarmos para as salas de aula, e essas atividades são feitas pelas crianças com assuntos diversos através de música, teatro, leitura, brincadeiras, jograis. Então, foi acordado pelo coletivo educador que um dia da semana seria falado sobre o novo vírus e, bem sutilmente, a escola começou a socializar informações sobre os dados atualizados deste grande perigo.

Iniciou-se com dados mundiais, depois os dados nacionais e percebendo a velocidade da transmissão do vírus a escola começou a ensinar as formas de se proteger para não adquirir o vírus. Gradativamente, foi-se trabalhando sobre este grave problema, mas nunca imaginávamos que estávamos à beira de uma quarentena que pareceria infinita. Foi então que veio a notícia: As escolas irão fechar!

A maior preocupação era com o emocional e as necessidades básicas dos educandos que, em sua maioria, encontram na escola um porto seguro e um ponto de referência. Por conta própria, ou seja, sem orientações da Secretaria de 
Educação, passou-se a enviar atividade online, via aplicativo de troca de mensagens para as crianças realizarem em casa, somente para manterem o contato com a leitura, escrita e matemática, atividades de artes, para se sentirem um pouco mais alegres e algumas sugestões de brincadeiras para realizarem com as famílias. A equipe diretiva também imprimia atividades físicas para que as famílias que não tivessem acesso à internet pudessem ir até a escola e retirar o material.

Entre tantas preocupações, entre diferentes sensações emocionais, de dúvidas, medo, inseguranças e saudades, pode-se contar com a tão necessária e presente, neste momento, tecnologia. Foi por meio da tecnologia, aquela que há anos nos prometia ser essencial, que foi possível manter as pessoas conectadas e com o sentimento de estarem "vivas" diante do desafiador cenário que a Covid19 apresentou. A tecnologia trouxe para dentro das casas a possibilidade de viajarmos, pela casa de nossos amigos, parentes e pessoas queridas e, também, trouxe até nós a possibilidade aprendermos dentro do conforto do nosso lar.

Porém, na maioria dos casos, o ensino remoto é pensado em um contexto tecnológico, como foi o caso apresentado em uma capacitação oferecida pela. Secretaria Municipal de Educação para os professores de Nova Santa Rita. Além da falta de acesso à internet, outro empecilho para a implementação do ensino remoto é a falta de equipamentos adequados para o estudo domiciliar. Em publicação do Comitê Gestor da Internet, o celular é a única forma de acesso à internet para $85 \%$ das camadas D/E e para $61 \%$ da camada C (VALENTE, 2018). E de acordo com a última pesquisa anual do uso de TI realizada pela Fundação Getúlio Vargas (2020), o Brasil tem dois aparelhos celulares por habitante, no entanto, não encontramos nenhuma pesquisa que mostre a quantidade de aparelhos por núcleo familiar, e na realidade de muitos dos nossos alunos não chega nem a dois celulares por domicílio.

A capacitação que foi oferecida era muito boa, a palestrante dominava o assunto, tinha muita coerência no seu "modelo" de trabalho, muito oportuno para as escolas particulares, inclusive, porém, não contemplava a forma de trabalho e ensino das escolas do campo, ou seja, não contextualizava nossa realidade. Então, em uma reunião online, o coletivo educador decidiu que o trabalho iria ocorrer conforme as necessidades da comunidade escolar e seu contexto, pois a 
maioria da comunidade escolar não possuía acesso à internet e a computadores, e a fração que possuía esse acesso, acabava por encontrar o entrave referente à sinal de qualidade.

Em maio de 2020, o coletivo educador foi comunicado que receberia uma formação, para montar uma apostila com atividades que valeriam como aula à distância, durante a pandemia, as quais seriam enviadas a partir de julho. A gestão municipal optou por não realizar aulas online, somente impressões físicas para que todas as crianças fossem contempladas, sem exclusão, como ocorreu em 95\% das estratégias pedagógicas adotadas no Brasil.

De acordo com as Diretrizes Operacionais para a Educação Básica nas Escolas do Campo "O campo...mais do que um perímetro não urbano, é um campo de possibilidades que dinamizam a ligação dos seres humanos com a própria produção das condições da existência social e com as realizações da sociedade humana" (CNE/CEB 1, 2002, p. 1). Sendo assim, a Educação do Campo pode ser caracterizada como um processo de ocupação que se faz em movimento e por movimentos.

\begin{abstract}
A identidade da escola do campo é definida pela sua vinculação às questões inerentes à sua realidade, ancorando-se na temporalidade e saberes próprios dos estudantes, na memória coletiva que sinaliza futuros, na rede de ciência e tecnologia disponível na sociedade e nos movimentos sociais em defesa de projetos que associem as soluções exigidas por essas questões à qualidade social da vida coletiva no país. (CNE/CEB 1, 2002, p. 1).
\end{abstract}

Logo, a E.M.E.F Rui Barbosa ensina por meio de um currículo pensado especialmente para os educandos do campo, escolhendo Eixos Temáticos que contemplem o território educador da escola, sejam adequados para cada faixa etária e, ainda, que partem da curiosidade dos educandos, de um problema a partir da realidade deles ou até mesmo de algo que seja referência positiva dentro da comunidade, que faça parte do cotidiano dos educandos. Para isso continuar ocorrendo, elaborou-se seis apostilas diferentes, uma para cada mês (julho, agosto, setembro, outubro, novembro e dezembro) voltada para revisões, pois, conforme orientação da Secretaria Municipal de Educação, não se poderia aplicar conteúdos novos.

A apostila de julho foi pensada com muito carinho, contento atividades que fizessem com que os educandos refletissem, percebessem e escrevessem sobre 
seus sentimentos e angústias, que os motivassem a refletirem sobre o atual momento e sobre um esperançar de novas possibilidades. A apostila trabalhou com textos que estimulassem percepção dos seus sentimentos e a visão de que esse momento iria passar e que logo estaríamos juntos novamente.

A apostila de agosto possibilitou às famílias e as crianças brincarem como se fossem jornalistas. O objetivo era construir um jornal a partir do contexto da sua comunidade e dos acontecimentos durante o período de pandemia. Também foram abordadas atividades que, novamente, estimulassem a reflexão dos seus sentimentos neste momento tão delicado de isolamento e incertezas.

Para o mês de setembro, a apostila foi organizada com textos que resgataram a história da escola desde suas primeiras atividades, motivando os educandos a pesquisarem com suas famílias (com os devidos distanciamentos) algumas curiosidades desde seus tempos de crianças que envolvessem a história do assentamento Capela e a participação com a escola. Neste mês, foram enviadas às famílias sementes de girassóis (símbolo das escolas do campo) para que os educandos plantassem e cuidassem, juntamente com seus familiares. Uma atividade que foi pensada para que as crianças tivessem um objetivo, um compromisso a cumprir, aproximando seu dia a dia com a escola.

$\mathrm{Na}$ tentativa de reaproximar a escola dos educandos, no mês de outubro, a apostila conteve atividades voltadas à história do Clube de Ciências e todas as suas conquistas, trazendo para os educandos e suas famílias boas lembranças da escola e das suas atividades, buscando reforçar o elo dos projetos que movem a escola às famílias.

No mês de novembro, o eixo temático foi a Consciência Negra, todas as educadoras planejaram atividades que contemplassem esta temática, sempre aliando ao contexto e as histórias da realidade e do território das nossas crianças.

Notando uma certa adaptação e uma fala de mais aceitação do atual momento pela comunidade, a apostila de dezembro trouxe o tema Natal para que os educandos se sentissem em clima de festas e de férias, pois o ano já havia passado e eles sabiam que não retornaríamos mais durante 2020.

Reforçamos que as entregas das apostilas foram feitas no início de cada mês respectivo para os pais ou responsáveis pelos educandos e que as educadoras se mantiveram disponíveis em aplicativos de trocas de mensagens 
para solucionar dúvidas e auxiliar nas dificuldades que poderiam vir a surgir por parte das crianças.

\section{ANÁLISE E DISCUSSÃO}

Lugar de criança sempre foi na escola, com um profissional qualificado ao seu lado, para lhe orientar e dar todo o suporte necessário. Além da presença do educador, é claro, que os pequenos precisam dos colegas, afinal são entre eles que acontece a troca de experiências, a criação de laços e o mais importante, o crescimento e a diversão.

Desde que as escolas tiveram suas aulas presenciais suspensas, em março de 2020, por conta da pandemia de coronavírus, as famílias brasileiras, o coletivo educador e principalmente os educandos tiveram que se adaptar à uma nova rotina: crianças em casa o tempo todo, aulas de modo remoto, isolamento, entre outras mudanças. A realidade enfrentada agora é outra e ficou nas mãos dos profissionais da educação buscar novas ferramentas para rever e inovar 0 ensino, pois nem todas as práticas que funcionavam anteriormente se aplicam no sistema remoto, e, também, nas mãos das famílias, que precisaram colaborar e incentivar as crianças em seus momentos de aprendizagem.

Tendo em vista que a escola tratada neste trabalho é uma escola pública do campo e, conforme Arroyo (1982), a Educação do Campo é positivamente diferente, pois "o tratamento específico da educação rural, teria, pois, dois fundamentos: a condição carente do homem do campo ou sua pobreza econômica e, em contraste, sua riqueza cultural", o objetivo das apostilas era sempre contemplar as necessidades dos educandos, os seus sentimentos, as suas angústias, seus desejos, suas carências. Nunca se pensou em apenas ocupar o tempo livre dos educandos com qualquer atividade retirada da internet, sempre se pensou a atividade com o objetivo de que as crianças se encontrassem acolhidas por cada exercício que foi enviado, que permitisse que cada uma fosse tocada a pensar sobre si e sobre o material selecionado. A intenção sempre foi estimular a reflexão e as ações das crianças, tanto das famílias, a história da escola, os projetos de que gostavam, a consciência negra e o Natal.

Embora cada apostila tivesse sido pensada com todo 0 carinho, abrangendo as necessidades das crianças, algo não funcionou. O retorno das 
atividades não foi como esperado, infelizmente. No mês de setembro, as apostilas tiveram que ser devolvidas pelas famílias para que fossem analisadas pelas educadoras. Notou-se um pequeno número de retorno das atividades, o que ficou claro a falta de incentivo das famílias às atividades escolares dos seus filhos. Essa dificuldade já era esperada, principalmente porque, segundo especialistas, os pais não estão preparados pedagogicamente para atender às necessidades das crianças.

Porém, Gokhale (1980) relata que a família não é apenas o berço da cultura e a base para um futuro melhor, mas é também o centro da vida social. A educação bem-sucedida da criança no ambiente familiar é que vai servir de apoio à sua criatividade e ao seu comportamento produtivo quando for adulto. A família tem sido, é e será a influência mais poderosa para o desenvolvimento da personalidade e do caráter das pessoas.

Conforme o gráfico 1, que representa as entregas das apostilas da turma do quinto ano que é multisseriada com os educandos do quarto ano, percebe-se que somente no mês de julho se teve 100\% das apostilas entregues.

Figura 1: gráfico do retorno das apostilas conforme cada mês:

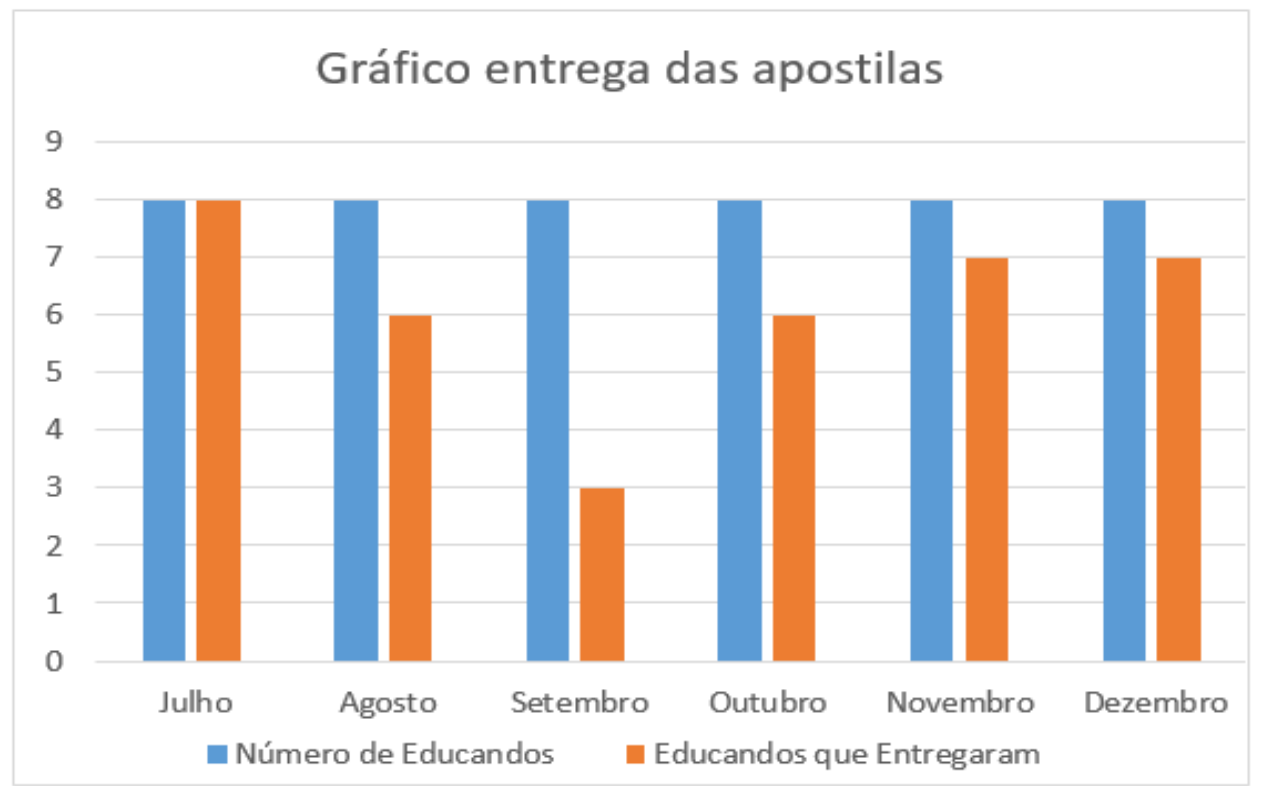

Fonte: Elaboração própria, 2021.

No mês de julho, todos os educandos entregaram as apostilas, porém, um deles não conseguiu completar todas as atividades. No mês de agosto, dos seis educandos que entregaram as apostilas, três não conseguiram fazer todas as 
atividades. O mês de setembro, foi muito curioso, apenas três entregaram, sendo que dois deles realizaram parcialmente as atividades. No mês de outubro, dos seis que entregaram, três não conseguiram realizar todas as atividades. No mês de novembro, observou-se uma queda drástica, pois apenas dois educandos entregaram a apostila praticamente em branco. Em dezembro, três educandos não conseguiram realizar todas as atividades, sendo que duas estavam praticamente em branco.

Vale ressaltar que a preocupação maior não seria quanto ao número de educandos que entregaram, pois, a maioria entregou, o que preocupou foram as apostilas entregues que não estavam completas e alguns exercícios ainda foram realizados por familiares, pois fica nítido que a caligrafia não era do educando. Essa falta de constância se apresentou como um desafio para as famílias. Depois de meses em ensino remoto e com menor contato com o mundo exterior, é normal que tanto os pais quanto as crianças estejam cansados e desanimados. Além das aulas remotas, também é pedido aos pais que façam as tarefas e as atividades em conjunto, o que pode acabar sobrecarregando toda a família e sua rotina, não apenas as crianças.

Mesmo com as dificuldades, procuramos sensibilizar os educandos e famílias do quanto é importante persistir, pois o que é aprendido agora fará, sim, diferença no futuro e abandonar o ensino remoto significa não só o educando deixar de aprender, mas, também, perder parte do conteúdo que ele já aprendeu em outros momentos. Quando a criança fica muito tempo longe das atividades, o cérebro vai enfraquecendo as ligações que já foram feitas.

\section{CONSIDERAÇÕES FINAIS}

Durante o período de pandemia, com o distanciamento dos educandos da escola, ficou aparente a importância da família na formação educacional dos educandos, pois quando as crianças não têm o incentivo e o apoio para os estudos, principalmente no início de sua caminhada educacional, fica difícil de se comprometerem com suas atividades. Certamente a família faz a diferença na vida escolar de uma criança.

A presença do educador, seu olhar, seu estímulo, suas cobranças, seu toque, seu carinho faz toda a diferença na vida escolar de uma criança. A distância 
dos educandos da escola e de seus mestres, causada pela pandemia, foram decisivos para entendermos que, para determinadas crianças, o professor é o único recurso de amparo e incentivo para o seu desenvolvimento educacional.

Percebeu-se que a implementação do ensino remoto tornou ainda mais evidente a precariedade da vida dos alunos e professores das escolas públicas brasileiras, e como as condições de desigualdade afetam o acesso à educação. Os resultados demonstram que apesar do uso de apostilas e do uso dos aplicativos de trocas de mensagens, como instrumentos de ensino remoto sejam uma estratégia muito utilizada, deve-se levar em consideração as vivências e sentimentos dos educandos envolvidos nesse processo, respeitando a individualidade, singularidade e carência emocional de cada um, valorizando sua trajetória e maneira própria de estar no mundo. 


\section{REFERÊNCIAS}

Arroyo, m. G. Escola cidadania e participação no campo. Em aberto, v. 1, n. 9, p. 1-6, 1982.

Bermúdez, a. C.; rezende, c.; madeiro, c. Brasil é o $7^{\circ}$ país mais desigual do mundo, melhor apenas do que africanos. Uol, são paulo/maceió, 09 dez. 2019. Disponível em: https://bit.ly/3nrsspu. Acesso em: 10 out. 2020.

Coletivo de estudos em marxismo e educação. Em defesa da educação pública comprometida com a igualdade social: porque os trabalhadores não devem aceitar aulas remotas. Esquerda online, rio de janeiro, 30 abr. 2020. Disponível em: https://bit.ly/351lzhl. Acesso em: 22 set. 2020.

Conselho nacional de educação câmara de educação básica. Resolução cne/ceb 1, de 3 de abril de 2002. Institui diretrizes operacionais para a educação básica nas escolas do campo. Brasília: cne/ceb, 2002.

Fundação getulio vargas. Brasil tem 424 milhões dispositivos digitais em uso, revela a $31^{\underline{a}}$ pesquisa anual da fgvcia. Fgv, 8 jun. 2020. Disponível em: https://bit.ly/33x8pmi. Acesso em: 09 jun. 2020.

Gokhale, s. D. A família desaparecerá? Revista debates sociais, rio de janeiro, n. 30, ano xvi, 1980.

Valente, j. Celular se torna principal forma de acesso à internet no brasil. Agência brasil, brasília, 24 jul. 2018. Disponível em: https://bit.ly/3npgqsn. Acesso em: 14 out. 2020. 